XLVIth Zakopane School of Physics, International Symposium Breaking Frontiers, Zakopane, Poland, May 16-21, 2011

\title{
Hydrothermal Synthesis of Hydroxyapatite on Titanium after Anodic Oxidation
}

\begin{abstract}
A. Strzata ${ }^{a, *}$, W. SimkA ${ }^{b}$ AND M. MARSZAlEK ${ }^{a}$
${ }^{a}$ The Henryk Niewodniczański Institute of Nuclear Physics, Polish Academy of Sciences, Kraków, Poland

${ }^{b}$ Faculty of Chemistry, Silesian University of Technology, Gliwice, Poland

Hydrothermal synthesis of hydroxyapatite (HA) is a method which is relatively easy to apply and enables HA precipitation on substrates of various shapes, which is vital to endoprostheses fabrication. Anodic oxidation facilitates HA precipitation, making the coating thicker and more uniform. In this paper the influence of anodic oxidation of titanium substrates on HA precipitation in hydrothermal synthesis is discussed. To determine chemical composition and coating uniformity of anodised and polished Ti substrates the Raman microspectroscopy was employed. The composition was also confirmed using X-ray diffraction method. HA coatings on Ti after anodic oxidation exhibit higher uniformity in comparison to untreated Ti. The X-ray diffraction patterns showed that the HA coating was partly amorphous. Also influence of additional treatment (soaking in $\mathrm{NaOH}$ and/or HBSS) after anodic oxidation is discussed in the present paper. It seems that pretreatment may be favourable in some cases, but if the anodic oxidation was conducted in the presence of calcium phosphates the pretreatment seems to prevent the HA precipitation.
\end{abstract}

PACS: 85.85.+j, 81.20.Ka, 82.80.Gk, 87.64.Bx, 87.85.J-

\section{Introduction}

Hydroxyapatite $\mathrm{Ca}_{10}\left(\mathrm{PO}_{4}\right)_{6}(\mathrm{OH})_{2}(\mathrm{HA})$ is the mineral bone component, so, its biocompatibility and bioactivity is excellent [1]. That is why synthetic HA has numerous biomedical applications, both orthopaedic and dental [2]. Due to its poor mechanical properties [3] HA cannot be used as a bulk implant material. HA is therefore used as a coating material on metallic implants, such as titanium and its alloys. Titanium is one of the most widely used materials in endoprosthesis fabrication because of its high biocompatibility [4], but its osseointegration is relatively poor, as compared to calcium phosphate materials.

There are different methods used for forming HA coatings on $\mathrm{Ti}$ and its alloys. The relatively cheap and simple technique is hydrothermal method [4-10]. Different solutions are used to obtain HA coating with this method, one of them is a solution containing $\mathrm{EDTA}^{4-}, \mathrm{Ca}^{2+}$ and $\mathrm{PO}_{4}^{3-}[5-7]$, another - Hank's solution $[4,8,9]$ or simulated body fluid (SBF) [10]. To ensure the reasonable growth rate and good adhesion of $\mathrm{HA}$ on titanium surface the preparation of the substrate is of great importance.

Anodic oxidation is a good method for obtaining bioactive surface of titanium because it allows preparation of oxide films on titanium, which facilitate HA precipitation in presence of body fluids [11-13]. Solutions used in this process often contain calcium and/or phosphorus $[14,15]$ which should also facilitate HA precipitation on titanium surface by attachment of positively charged calcium ions to oxide layer and their subsequent binding to negatively charged phosphate ions. It was also shown [15] that the apatite layer can be formed on titanium

* corresponding author; e-mail: Alicja.Strzala@ifj.edu.pl surface after soaking in $\mathrm{NaOH}$ and subsequent heating. This results in formation of $\mathrm{Ti}-\mathrm{OH}$ groups which promotes calcium and phosphate bonding to titanium.

In this study the authors discuss influence of anodic oxidation and subsequent chemical treatment on the process of hydroxyapatite precipitation in hydrothermal synthesis. Samples were subjected to the anodic oxidation in phosphoric acid or the mixture of phosphoric acid and sodium or calcium hypophosphite. The samples were next soaked in $5 \mathrm{M} \mathrm{NaOH}$ followed by soaking in Hank's solution. All samples were investigated after each step of chemical treatment by means of optical microscopy, the Raman microspectroscopy and X-ray diffraction.

\section{Materials and methods}

Commercially pure titanium (99.9\%, Koch-Light Laboratory Ltd, Colnbrook) was cut into samples of dimensions $5 \times 10 \times 2.5 \mathrm{~mm}^{3}$. All samples were then polished using water emery paper $\# 600,800$ and 1000 , and degreased in ultrasonic bath for $10 \mathrm{~min}$ in each of the following solvents: hexane, acetone and ethanol [16]. After each solvent use the samples were rinsed with deionised water and dried in ambient air. Then the samples were divided into five groups (A to E). Control group (A) after polishing and degreasing was not exposed to further modification; group B was immersed in $5 \mathrm{M} \mathrm{NaOH}$ at room temperature for $24 \mathrm{~h}$ and then in Hank's solution (HBSS) also at room temperature for $24 \mathrm{~h}$. Groups C, D and $\mathrm{E}$ were anodised in three solutions (see Table I) [11]. The voltages of the anodising process are also presented in Table I. After anodising, the samples were rinsed with distilled water and cleaned ultrasonically with 2-propanol and deionized water. For the purpose of anodising, a DC power supply (PWR800H, Kikusui, Japan) was used. 
The anode was the $\mathrm{Ti}$ specimen and the cathode was a titanium plate. Next the samples from groups $\mathrm{C}, \mathrm{D}$ and $\mathrm{E}$ were then soaked in $5 \mathrm{M} \mathrm{NaOH}$ for $24 \mathrm{~h}$ at room temperature and then in Hank's solution also for $24 \mathrm{~h}$ at room temperature. The details of sample preparation are shown in Table II.

TABLE I

The chemical composition of solutions used for the anodisation of the titanium samples and the voltage of the process.

\begin{tabular}{c|c|c|c|c}
\hline \hline $\begin{array}{c}\text { Sample } \\
\text { group }\end{array}$ & $\begin{array}{c}\mathrm{H}_{3} \mathrm{PO}_{4} \\
{[\mathrm{M}]}\end{array}$ & $\begin{array}{c}\mathrm{NaH}_{2} \mathrm{PO}_{2} \\
{\left[\mathrm{~g} \mathrm{dm}^{-3}\right]}\end{array}$ & $\begin{array}{c}\mathrm{Ca}\left(\mathrm{H}_{2} \mathrm{PO}_{2}\right)_{2} \\
{\left[\mathrm{~g} \mathrm{dm}^{-3}\right]}\end{array}$ & $\begin{array}{c}\mathrm{U} \\
{[\mathrm{V}]}\end{array}$ \\
\hline $\mathrm{C}$ & 4 & - & - & 80 \\
$\mathrm{D}$ & 4 & 20 & - & 150 \\
E & 4 & - & 20 & 150
\end{tabular}

TABLE II

The sample labels and treatment condition: "+" with treatment; "-" without treatment.

\begin{tabular}{c|c|c|c}
\hline \hline \multirow{2}{*}{ Sample } & \multicolumn{3}{|c}{ Treatment condition } \\
\cline { 2 - 4 } & Anodising & $\begin{array}{c}\text { NaOH } \\
\text { treatment }\end{array}$ & $\begin{array}{c}\text { HBSS } \\
\text { treatment }\end{array}$ \\
\hline A & - & - & - \\
B & - & + & + \\
C1 & + & - & - \\
C2 & + & + & + \\
D1 & + & - & - \\
D2 & + & + & + \\
E1 & + & - & - \\
E2 & + & + & +
\end{tabular}

All samples after pre-treatment described above were subjected to hydrothermal synthesis which was performed in laboratory autoclaves that enable reactions at temperature up to $300^{\circ} \mathrm{C}$ and under pressure up to $20 \mathrm{MPa}$, without using large volume of solutions (Laboratory Autoclave Model II, Roth, GE). The synthesis was carried out in $100 \mathrm{~cm}^{3}$ of Hank's solution at temperature of $200{ }^{\circ} \mathrm{C}$ and the reaction time varied from $5 \mathrm{~h}$ to $11 \mathrm{~h} 10 \mathrm{~min}$. All used reagents were of analytical grade without further purification (POCh, PL).

Prepared samples were measured using high resolution confocal Raman microspectroscopy Nicolet Almega XR equipped with laser of wavelength of $532 \mathrm{~nm}$ in spectral range from 100 to $4000 \mathrm{~cm}^{-1}$. Pictures of the precipitated coatings were made with optical microscope attached to Nicolet Almega XR spectrometer. The Raman spectra of the samples were studied using computer application OMNIC for Nicolet Almega v. 7.3.

Further X-ray diffraction measurements were conducted using Panalytical X'PERT PRO Diffractometer operated at $40 \mathrm{kV}$ and $30 \mathrm{~mA}$ with monochromated $\mathrm{Cu} K_{\alpha}$ radiation.

\section{Results and discussion}

The anodising of titanium at $80 \mathrm{~V}$ (group $\mathrm{C}$ ) in the first bath ( $4 \mathrm{M} \mathrm{H}_{3} \mathrm{PO}_{4}$ ), led to a compact oxide film of a celadon colour. The morphology of the so anodized samples virtually did not vary from the morphology of the etched titanium [11]. During anodising of titanium at a voltage of $80 \mathrm{~V}$ phosphorus was not incorporated into the oxide layer. An increase in voltage to $150 \mathrm{~V}$ (groups D and E) caused the forming of a film consisting of phosphorus or/and calcium into the oxide layer with a porous structure as a result of spark anodizing [11-13]. The obtained film had a grey and white colour. Phosphate ions are present both in hydroxyapatite and in solutions used in anodic oxidation, that is why the Raman spectroscopy was employed to study the anodised Ti substrate before hydrothermal synthesis. The results are shown in Fig. 1.

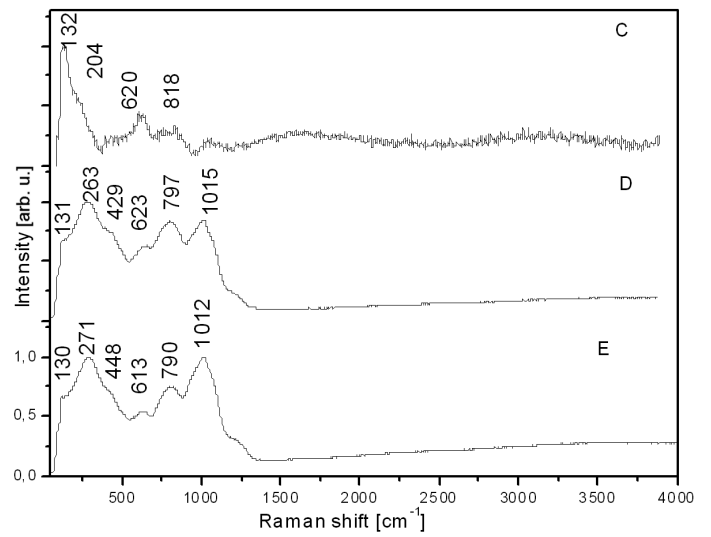

Fig. 1. Raman spectra of titanium surface after anodic oxidation (groups C, D, E, see Table I).

For a sample anodised at $80 \mathrm{~V}$ (Fig. 1C) peaks at 132, 204,620 , and $818 \mathrm{~cm}^{-1}$ can be seen. For sample anodised at $150 \mathrm{~V}$ in the presence of $\mathrm{NaH}_{2} \mathrm{PO}_{2}$ (Fig. 1D) peaks at $131,263,429,623,797$, and $1015 \mathrm{~cm}^{-1}$ are present. The oxide layer at samples D and E was also identified as mixture of anatase $\left(131 \mathrm{~cm}^{-1}\right)$ and rutile (263 and $\left.797 \mathrm{~cm}^{-1}\right)$ with incorporated [11] phosphate film (429, 623 , and $\left.1015 \mathrm{~cm}^{-1}\right)$. For sample anodised at $150 \mathrm{~V}$ in the presence of $\mathrm{Ca}\left(\mathrm{H}_{2} \mathrm{PO}_{2}\right)_{2}$ (Fig. $1 \mathrm{E}$ ) peaks at 130, 271, 448, 613, 790, and $1012 \mathrm{~cm}^{-1}$ can be seen.

Peak at $620 \mathrm{~cm}^{-1}$ present in spectrum of Ti anodised at $80 \mathrm{~V}$ which is characteristic for $\nu_{4}$ vibrations of $\mathrm{PO}_{4}^{3-}$ bonds probably is a result of a meager precipitation of phosphates from $\mathrm{H}_{3} \mathrm{PO}_{4}$ used in the anodisation.

Then the spectra were compared to reference spectrum of commercially pure HA purchased at Merck (GE) using the same device and conditions of analysis. The details of reference HA spectrum are presented in Table III. Peaks at 613 (group E), 620 (group C) and 623 (group D) $\mathrm{cm}^{-1}$ can be identified as peaks coming from vibrations $\nu_{4}$ of $\mathrm{PO}_{4}^{3-}$ bonds and are close to the same vibration type in pure HA $\left(591 \mathrm{~cm}^{-1}\right)$. Also peaks at 1012 (group E) and 1015 (group D) $\mathrm{cm}^{-1}$ can be assigned to $\nu_{3}$ vibrations of 


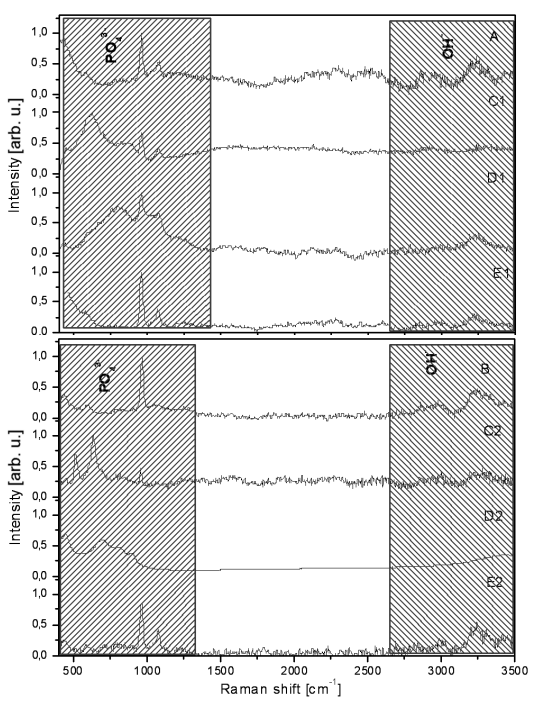

Fig. 2. Raman spectra of HA coating obtained on Ti: A - without any modification; C1, D1, E1 - after anodic oxidation; B - after immersion in $5 \mathrm{M} \mathrm{NaOH}$ and HBSS; C2, D2, E2 - after anodic oxidation and immersion in $5 \mathrm{M} \mathrm{NaOH}$ and HBSS (see Table I). The marked areas show spectral ranges of $\mathrm{PO}_{4}^{3-}$ and $\mathrm{OH}^{-}$ peaks characteristic for HA presence.
$\mathrm{PO}_{4}^{3-}$ bonds which are close to the same vibrations in $\mathrm{HA}$ $\left(1042 \mathrm{~cm}^{-1}\right)$. Therefore the analysis of HA film spectra in this spectral range requires special precautions.

\section{TABLE III}

Raman shifts for commercially pure HA (Merck, GE). The most intense peak in the spectrum is in bold.

\begin{tabular}{c|c|c|c|c|c}
\hline \hline Vibration & $\mathrm{PO}_{4}^{3-}$ & $\mathrm{PO}_{4}^{3-}$ & $\mathrm{PO}_{4}^{3-}$ & $\mathrm{PO}_{4}^{3-}$ & $\mathrm{OH}^{-}$ \\
& $\nu_{2}$ & $\nu_{4}$ & $\nu_{1}$ & $\nu_{3}$ & $\nu_{1}$ \\
\hline pure HA & 431 & 591 & $\mathbf{9 6 2}$ & 1042 & 3575
\end{tabular}

The Raman spectra of hydroxyapatite coatings obtained on non-modified $\mathrm{Ti}$ and anodised $\mathrm{Ti}$ additionally modified are shown in Fig. 2. The bands associated with the vibrations of the molecular groups occurring in HA are following: vibrations $\nu_{1}, \nu_{2}, \nu_{3}$ and $\nu_{4}$ of $\mathrm{PO}_{4}^{3-}$ and $\nu_{1}$ of $\mathrm{OH}^{-}$. In Table IV the main Raman lines from the vibrations of $\mathrm{PO}_{4}^{3-}$ and $\mathrm{OH}^{-}$vibrations in $\mathrm{HA}$ samples are listed.

In the spectrum of HA coating obtained on non-modified Ti the peak at $962 \mathrm{~cm}^{-1}$ is the most intensive one. Also peak at $1075 \mathrm{~cm}^{-1}$ is clearly visible. All other spectra are analysed comparatively to this reference spectrum in order to determine the influence of anodisation and/or additional soaking in $\mathrm{NaOH}$ and HBSS on $\mathrm{HA}$ precipitation.

Raman shifts for HA coating obtained on non-modified Ti and Ti after anodic oxidation.

TABLE IV

\begin{tabular}{c|c|c|c|c|c|c|c|c}
\hline \hline Vibration & Group A & Group B & Group C1 & Group C2 & Group D1 & Group D2 & Group E1 & Group E2 \\
\hline $\mathrm{PO}_{4}^{3-} \nu_{2}$ & 416 & 431 & 451 & 436 & 435 & 447 & 466 & - \\
$\mathrm{PO}_{4}^{3-} \nu_{4}$ & 584 & 591 & 623 & 635 & - & - & - & 611 \\
$\mathrm{PO}_{4}^{3-} \nu_{1}$ & 962 & 966 & 964 & 957 & 962 & 960 & 963 & 962 \\
$\mathrm{PO}_{4}^{3-} \nu_{3}$ & 1075 & 1074 & 1076 & 1060 & 1074 & - & 1072 & 1072 \\
$\mathrm{OH}^{-} \nu_{1}$ & 3573 & 3242 & - & 3312 & 3239 & 3389 & 3231 & 3244 \\
\hline
\end{tabular}

The Raman spectra of HA obtained on anodised Ti are different from reference spectrum of $\mathrm{HA}$ on non-modified Ti. For samples $\mathrm{C} 1$ and $\mathrm{C} 2$ vibrations $\nu_{4}$ of $\mathrm{PO}_{4}^{3-}$ bonds (623 and $635 \mathrm{~cm}^{-1}$, respectively) are much more intense than for other spectra. Their Raman intensity is also greater than the peaks coming from vibrations $\nu_{1}$ of $\mathrm{PO}_{4}^{3-}$ bonds (964 and $957 \mathrm{~cm}^{-1}$, respectively). This may indicate non-crystalline structure of the coating or presence of other calcium phosphates which may convert into HA. For HA coatings obtained on $\mathrm{Ti}$ anodised at $150 \mathrm{~V}$ (groups D1 and E1) the most intensive peaks are peaks coming from $\nu_{1}$ vibrations of $\mathrm{PO}_{4}^{3-}$ bonds $(962$ and $963 \mathrm{~cm}^{-1}$, respectively), peaks occurring at 1074 or $1072 \mathrm{~cm}^{-1}$ are weaker. That is why these coatings were identified as HA.

Analysis of the Raman spectra of groups B and $\mathrm{C} 2-\mathrm{E} 2$, for which peaks characteristic for $\mathrm{PO}_{4}^{3-}$ bonds are present, indicates that additional soaking of the $\mathrm{Ti}$ substrates in $5 \mathrm{M} \mathrm{NaOH}$ and HBSS facilitated calcium phosphates precipitation on non-modified $\mathrm{Ti}$ and anodised Ti.

The intensive peak coming from vibrations $\nu_{1}$ of $\mathrm{PO}_{4}^{3-}$ occurs at about $960 \mathrm{~cm}^{-1}$ which supports coating identification as HA. Also other peaks characteristic for $\mathrm{PO}_{4}^{3-}$ bonds in HA (416-466, 584-635, 1060-1075 cm-1) appear in all samples. Peaks appearing about 3200$3500 \mathrm{~cm}^{-1}$ assigned to $\mathrm{OH}^{-}$bands are also characteristic for HA. This indicates that hydroxyapatite precipitated on the surface of both non-modified and anodised titanium.

For some spectra (C1, C2, D1, D2) other calcium phosphate phases such as octacalcium phosphate (OCP, peak at about $870 \mathrm{~cm}^{-1}$ for samples D1 and D2) or $\beta$ -tricalcium phosphate $\left(\beta\right.$-TCP, peak at about $770 \mathrm{~cm}^{-1}$ for samples $\mathrm{C} 1, \mathrm{C} 2$ and D2) were identified. 
In Fig. 3 optical microscope photographs of HA coatings are shown. HA coating is seen as bright spots on darker area of Ti substrate. For samples A and C1 the substrate is visible in many places. For samples B, D1 and E1 the substrate is virtually invisible. Immersing of samples in $5 \mathrm{M} \mathrm{NaOH}$ and HBSS seemed to interfere with $\mathrm{HA}$ precipitation on $\mathrm{Ti}$ anodised in the presence of phosphoric acid and calcium hypophosphite (E2) or sodium hypophosphite (D2). For samples from groups B and C alkali treatment and subsequent soaking in HBSS facilitated formation of the coating which can be seen as more uniform bright areas on the photos.

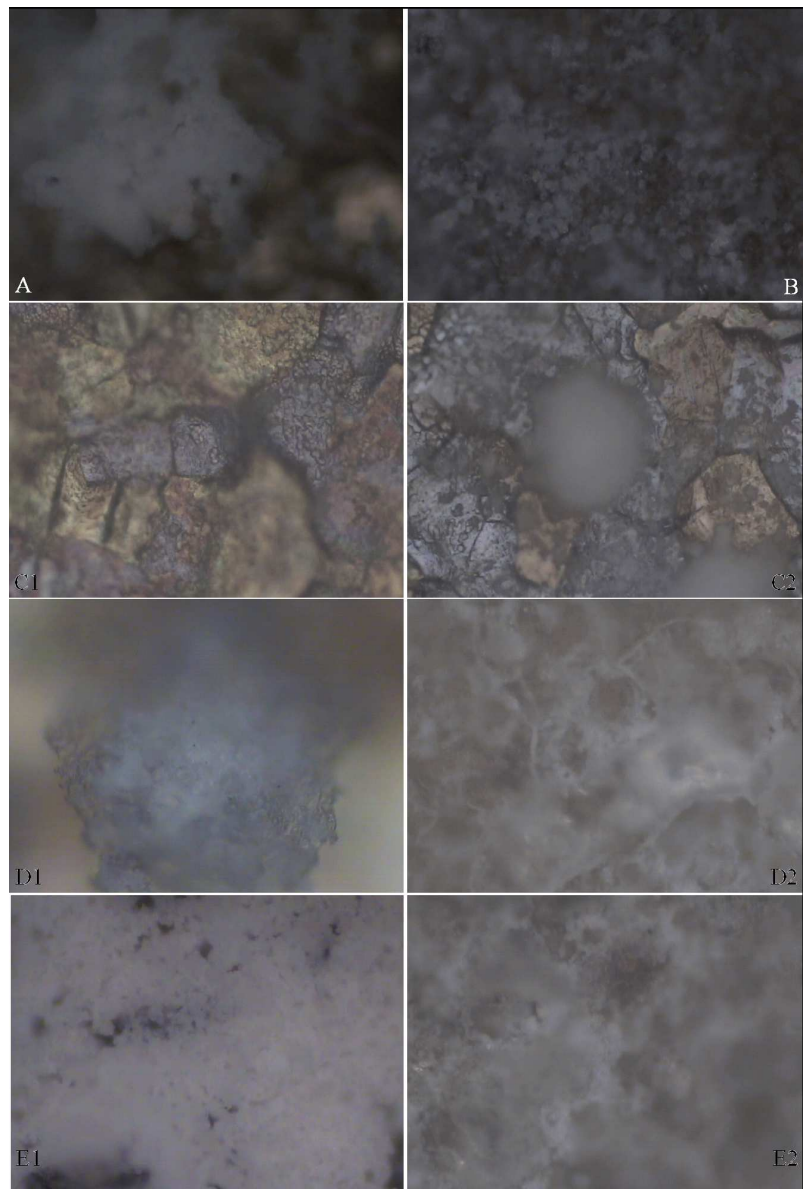

Fig. 3. Optical microscope view of HA coatings obtained on non-modified (A, B) and oxidized (C1-E2) Ti (see Table II).

XRD spectra of the samples are shown in Fig. 4. The peaks characteristic for crystal planes of HA are indicated in Fig. 4. All other peaks were identified as titanium peaks and they are due to the titanium substrate. The peak which occurred in all samples is the peak corresponding to crystal plane (1 30 ) of HA. In reference spectrum (ICSD: 01-089-6437) the relative intensity of the peak is about $20 \%$, and the most intense peak is the peak corresponding to crystal plane $\left(\begin{array}{lll}2 & 1 & 1\end{array}\right)$ at $2 \theta=31.8$. This peak occurs in spectra presented in this work for

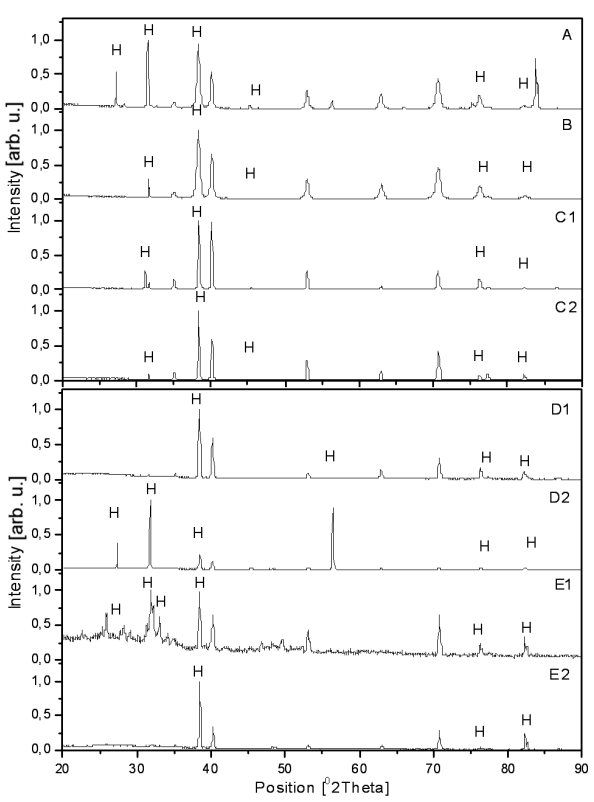

Fig. 4. XRD spectra of HA coatings obtained on non-modified (A, B) and anodised (C1-E2) Ti (see Table I).

groups A, B, C1, C2, D2 and E1. The intensities, however, are lower than in reference spectra (except from spectra for groups A and D2). This indicates that HA coating obtained in hydrothermal synthesis on $\mathrm{Ti}$ substrates prepared in described way may have a preferred orientation of growth.

Anodic oxidation of $\mathrm{Ti}$ substrates resulted in more intense HA peaks comparing to non-oxidized samples. However, for groups D1 and E1 amorphous tail may be seen at low scattering angles. For group E1 all peaks have larger FWHM which is probably caused by low sample crystallinity [17]. Additional treatment in $5 \mathrm{M} \mathrm{NaOH}$ and HBSS of samples $\mathrm{C} 2$ and D2 resulted in occurrence of more peaks related to HA.

Decreased intensity of the HA corresponding peaks might be caused by low crystallinity [14].

\section{Conclusions}

The authors discussed influence of anodic oxidation and subsequent chemical treatment of $\mathrm{Ti}$ substrates on the process of hydroxyapatite formation in hydrothermal synthesis. For all samples HA precipitates were obtained. In some cases other calcium phosphates were formed simultaneously with HA (samples C1, C2, D1, D2).

Anodic oxidation with phosphoric acid solution was an effective way to enhance HA precipitation in HBSS or SBF solutions on titanium surface. The most favourable method was anodic oxidation in the presence of sodium (group D) or calcium (group E) hypophosphite without further soaking in $5 \mathrm{M} \mathrm{NaOH}$ and HBSS. For non-oxidized samples (groups A and B) or anodised in phosphoric acid solution (group C) immersion in $5 \mathrm{M} \mathrm{NaOH}$ and HBSS facilitated HA precipitation on titanium. 


\section{Acknowledgments}

The project was partially supported by the grant of National Science Centre.

\section{References}

[1] Y. Zhang, T. Fu, Y. Han, Q. Wang, Y. Zhao, K. Xu, Biomol. Eng. 19, 57 (2002).

[2] C. Chang, J. Huang, J. Xia, C. Ding, Ceram. Int. 25, 479 (1999).

[3] M. Sato, E. Slamovich, T. Webster, Biomaterials 26, 1349 (2005).

[4] K. Hamada, M. Kon, T. Hanawa, K. Yokoyama, Y. Miyamoto, K. Asaoka, Biomaterials 23, 2265 (2002).

[5] Y. Fujishiro, M. Nishino, A. Sugimori, A. Okuwaki, T. Sato, J. Mater. Sci. Mater. Med. 12, 333 (2001).

[6] Y. Fujishiro, A. Fujimoto, T. Sato, A. Okuwaki, J. Colloid Interface Sci. 173, 119 (1995).

[7] A. Strzała, M. Marszałek, Eng. Biomater. 96-98, 16 (2010).

[8] A. Strzała, B. Petelenz, J. Kwiatkowska, B. Rajchel, Eng. Biomater. 92, 24 (2010).

[9] A. Strzała, M. Marszałek, Eng. Biomater. 106-108, 26 (2011).
[10] M. Calixtode Andrade, M. Tavares Filgueiras, T. Ogasawara, J. Eur. Ceram. Soc. 22, 505 (2002).

[11] W. Simka, A. Iwaniak, G. Nawrat, A. Maciej, J. Michalska, K. Radwański, J. Gazdowicz, Electrochim. Acta 54, 6983 (2009).

[12] W. Simka, A. Sadkowski, M. Warczak, A. Iwaniak, G. Dercz, J. Michalska, A. Maciej, Electrochim. Acta 55, 8962 (2011).

[13] W. Simka, Electrochim. Acta 55, 9831 (2011).

[14] B. Yang, M. Uchida, H.-M. Kim, X. Zhang, T. Kokubo, Biomaterials 25, 1003 (2004).

[15] X. Cui, H.-M. Kim, M. Kawashita, L. Wang, T. Xiong, T. Kokubo, T. Nakamura, Dent. Mater. 25, 80 (2009).

[16] G. Raikar, J. Geregory, J. Ong, L. Lucas, J. Lemons, D. Kawakara, M. Nakamura, J. Vac. Sci. Technol. A 13, 2633 (1995).

[17] C. Moseke, V.V. Pilipenko, O. Bölling, L.F. Sukhodub, B. Sulkio-Cleff, in: Mineralization of Hydroxyapatite under Influence of Metal Ions. Annual Report 2002/03, Westfälische Wilhelms-Universität Münster, Institut für Kernphysik, p. 81. 